\title{
6 OPEN ACCESS \\ Are there differences in injury mortality among refugees and immigrants compared with native-born?
}

\author{
Marie Norredam, ${ }^{1}$ Maja Olsbjerg, ${ }^{2,3}$ Jorgen H Petersen, ${ }^{2,3}$ Bjarne Laursen, ${ }^{3}$ \\ Allan Krasnik ${ }^{1}$
}

${ }^{1}$ Research Centre for Migration, Ethnicity and Health, Section of Health Services Research, Department of Public Health University of Copenhagen 2Department of Biostatistics, Department of Public Health University of Copenhagen, Copenhagen, Denmark ${ }^{3}$ The National Institute of Public Health, University of Southern Denmark, Copenhagen, Denmark

\section{Correspondence to} Dr Marie Norredam, Danish Research Centre for Migration Ethnicity and Health, Department of Public Health, University of Copenhagen, Denmark, Øster Farimagsgade 5, Building 10, 1014 Copenhagen K, Denmark; mano@sund.ku.dk

Accepted 17 April 2012 Published Online First 24 May 2012

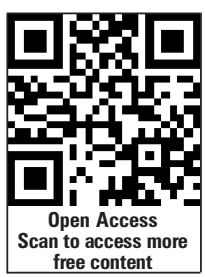

\section{ABSTRACT}

Background The authors studied injury mortality in Denmark among refugees and immigrants compared with that among native Danes.

Method A register-based, historical prospective cohort design. All refugees $(n=29139)$ and family reunited immigrants ( $n=27$ 134) who between 1 January 1993 and 31 December 1999 received residence permission were included and matched 1:4 on age and sex with native Danes. Civil registration numbers were crosslinked to the Register of Causes of Death, and fatalities due to unintentional and intentional injuries were identified based on ICD-10 diagnosis. Sex-specific mortality ratios were estimated by migrant status and region of birth, adjusting for age and income and using a Cox regression model after a median follow-up of $11-12$ years.

Results Compared with native Danes, both female $(\mathrm{RR}=0.44 ; 95 \% \mathrm{Cl} 0.23$ to 0.83$)$ and male ( $\mathrm{RR}=0.40$; $95 \% \mathrm{Cl} 0.29$ to 0.56 ) refugees as well as female $(\mathrm{RR}=0.40 ; 95 \% \mathrm{Cl} 0.21$ to 0.76$)$ and male ( $\mathrm{RR}=0.22$; $95 \% \mathrm{Cl} 0.12$ to 0.42 ) immigrants had significantly lower mortality from unintentional injuries. Suicide rates were significantly lower for male refugees $(R R=0.38 ; 95 \% \mathrm{Cl}$ 0.24 to 0.61$)$ and male immigrants $(\mathrm{RR}=0.24 ; 95 \% \mathrm{Cl}$ 0.10 to 0.59 ), whereas their female counterparts showed no significant differences. Only immigrant women had a significantly higher homicide rate $(\mathrm{RR}=3.09 ; 95 \% \mathrm{Cl} 1.11$ to 8.60$)$ compared with native Danes.

Conclusions Overall results were advantageous to migrant groups. Research efforts should concentrate on investigating protective factors among migrants, which may benefit injury prevention in the majority population.

Of the population in Denmark in 2010, immigrants and descendants constituted $9.8 \%$, of whom $2.3 \%$ were descendants and $7.5 \%$ immigrants. ${ }^{1}$ The majority $(61 \%)$ of immigrants come from nonWestern countries, the five most frequent countries of origin being: Turkey, Iraq, Lebanon, Bosnia and Pakistan. Divided by migrant status, Denmark has received 75000 refugees and 105000 family reunited immigrants within the past 15 years. ${ }^{2} 3$ Refugees enter Denmark as spontaneous asylum seekers or as quota refugees, whereas family reunited immigrants enter Denmark by their own means and rely entirely on their family when establishing life in the country of immigration. In this paper, family reunited immigrants are referred to as 'immigrants', while 'migrants' refer to all groups of foreign-born individuals.
Inequalities in mortality have been documented in several European countries among migrant populations compared with majority populations. $^{4-6}$ These inequalities vary according to specific causes of death. The few studies investigating injury mortality among migrants in a European context confirm increased mortality for all injuries combined; albeit differences were seen according to type of injury, ethnic group, sex and age. $^{7-9}$ As in these studies, our definition of injury mortality included mortality from both unintentional and intentional injuries. ${ }^{79}$

Studies of injury mortality among migrants are of interest because it could be assumed that migrants are especially vulnerable in this respect as they experience various risk factors related to injuries and injury mortality due to the inherent trauma of uprooting and the challenges of restabilising life in a new country: (1) migrants have a higher prevalence of mental disorders compared with native populations; ${ }^{10-12}$ (2) migrants experience discrimination and hate crimes; ${ }^{13}$ (3) migrants' socioeconomic status is often lower compared with native populations; ${ }^{1}$ (4) migrants more frequently work in unskilled high-risk jobs; ${ }^{14}$ and (5) migrants experience problems in accessing appropriate healthcare. ${ }^{15-17}$ These risk factors may alone or in combination result in higher injury mortality; this may especially be the case for vulnerable migrant groups such as refugees. Conversely, migration could hypothetically also be protective in relation to injuries. Building on the healthy migrant theory, one may argue that some migrant groups have a stronger health than native populations. ${ }^{6}$ Additionally, literature on risk behaviour show less substance abuse among migrants compared with host populations. ${ }^{18}$

No Nordic studies exist on injury mortality among migrants; however, a Danish study on unintentional injuries found lower injury rates among migrants' children compared with the children of native Danes. ${ }^{19}$ The scarcity of studies and the contrasting findings emphasise the need for more knowledge on injury mortality patterns among migrants compared with patterns among native populations. Additionally, existing studies divide populations according to ethnicity (country of origin) rather than migrant status (refugees vs family reunited immigrants). ${ }^{7-9}$ Consequently, we aimed to determine injury mortality, including both ethnic origin and migrant status, in a well-defined cohort of migrants and compare it with that among native Danes based on national data using the unique Danish possibilities of register-based national data. 


\section{MATERIAL AND METHODS}

\section{Study cohort}

The study cohort was obtained through the statistics department at the Danish Immigration Service. All individuals who obtained right of residency as refugees or through family reunification in Denmark from 1 January 1993 to 31 December 1999 were included; 84379 individuals were identified. The cohort was established on 1 January 1993 as this was the first year for which the Danish Immigration Service had valid registry information on all individuals obtaining residence permit. Next, we excluded individuals $<18$ years of age $(\mathrm{n}=18$ 861) when they obtained residency. Another 3042 individuals were excluded due to missing civil registration numbers or because their personal security numbers appeared more than once in the sample. Additionally, 15 migrants and their controls were excluded due to problems with their registration of nationality. A Danish-born reference population was identified through Statistics Denmark, and a 4:1 match on an individual level on age and sex was preformed through a random sampling procedure. We made a 4:1 matching for all refugees. Four of the immigrants were missing from a total of five controls due to difficulties with age matching because of outlying ages. The study cohort and matching procedure have previously been described in more detail. ${ }^{20}$ Last, 6188 migrants born in Western countries were excluded from the cohort with their corresponding controls. We excluded Western migrants because we expected patterns of injury-related mortality to differ from non-Western migrants due to differences in exposures to risk factors related to migration processes between these two groups. The final cohort comprised 29139 refugees (controls: 116556) and 27134 immigrants (controls: 108534). Migrants were consecutively censored on their first registered emigration date and were not included again if they later returned to Denmark. Follow-up time was thus defined for both refugees and immigrants and their corresponding controls as the time from the commencement of right of residency until the time of the first of the following events: (a) date of death; (b) end of study (31 December 2007); or (c) date of first emigration. Characteristics of the study population are shown in table 1.

\section{Data collection}

Civil registration numbers of the study cohort were cross-linked to the Danish Register on Causes of Death using the personal identification number, which is a unique 10-ciphre number that all Danish citizens receive. The Register on Causes of Death has data based on the report of death certificates to the National Board of Health. The register was updated to 31 December 2007. Death causes were coded according to the International Classification of Diseases (ICD), tenth revision. The register has used the ICD-10 coding system since 1 January 1994, a change from the ICD-8 coding system previously used. As the validity of the translations in the register from ICD-8 to ICD-10 is questionable, we decided to use only ICD-10 diagnoses starting from 1 January 1994. Among all deaths $(\mathrm{n}=9855)$ in the cohort, the cause of death was missing in 168 individuals and were consequently excluded from the study on their date of death. We identified all unintentional and intentional injury-related deaths from 1 January 1994 to 31 December 2007. Unintentional injuries included injuries with undetermined intent, meaning that in some cases it is not known from the record whether an individual died from accidental or by suicide (eg, in some cases of drowning). Unintentional injuries encompassed: falls (W00-W19); traffic injuries (V01-89;Y85); unintentional poisoning - not medication (X40-X49); and other causes (V90-V94, Y60-Y84, Y88, V95-V99, W20-W64, W75-99, X00-X39, X50-59, Y40-Y59, Y86). Intentional injuries included: all suicides (X60-X84, Y87.0) and homicides (X85-X99, Y00-Y09, Y87.1). This definition of injury mortality is in line with a previous Danish study. ${ }^{21}$ The cohort comprised 92 refugee (control: 598) and 48 immigrant (control: 377 ) deaths from injuries.

We analysed data by migrant status (refugees vs family reunited immigrants) and adjusted for region of origin according to the largest migrant groups in Denmark. We based our definitions of geographical areas on WHO guidelines: Asia, Eastern Europe, the former Yugoslavia, Iraq, the Middle East, North Africa and Sub-Saharan Africa. ${ }^{22}$ As Iraqis formed the largest

Table 1 Characteristics of the study cohort. Refugees $(n=29139)$ and immigrants $(27134)$ and their matched Danish-born control groups are distributed by sex

\begin{tabular}{|c|c|c|c|c|c|c|c|c|}
\hline & $\begin{array}{l}\text { Female } \\
\text { refugees } \\
\%(\mathbf{n})\end{array}$ & $\begin{array}{l}\text { Danes } \\
\% \text { (n) }\end{array}$ & $\begin{array}{l}\text { Male } \\
\text { refugees } \\
\%(\mathbf{n}) \\
\end{array}$ & $\begin{array}{l}\text { Danes } \\
\% \text { (n) }\end{array}$ & $\begin{array}{l}\text { Female } \\
\text { immigrants } \\
\%(\mathbf{n})\end{array}$ & $\begin{array}{l}\text { Danes } \\
\% \text { (n) }\end{array}$ & $\begin{array}{l}\text { Male } \\
\text { immigrants } \\
\%(\mathbf{n})\end{array}$ & $\begin{array}{l}\text { Danes } \\
\%(\mathbf{n}) \\
\end{array}$ \\
\hline \multicolumn{9}{|l|}{ Regional of origin } \\
\hline East Europe & $2.0(258)$ & & $1.8(297)$ & & $16.8(3100)$ & & $5.4(481)$ & \\
\hline Former Yugoslavia & $57.2(7404)$ & & $49.2(7965)$ & & 5.7 (1038) & & $9.8(856)$ & \\
\hline Iraq & $11.3(1464)$ & & $19.5(3154)$ & & $6.5(1185)$ & & $2.0(180)$ & \\
\hline Sub-Saharan Africa & $1.7(225)$ & & $1.9(305)$ & & $6.1(1121)$ & & $9.7(846)$ & \\
\hline Total & 100 (12 949) & $100(51796)$ & $100(16190)$ & $100(64760)$ & 100 (18 354) & $100(73416)$ & $100(8780)$ & $100(35118)$ \\
\hline Sex & 44.4 (12 949) & $44.4(51796)$ & $55.6\left(\begin{array}{llll}16 & 190)\end{array}\right.$ & $55.6(64760)$ & 67.6 (18 354) & $67.6(73416)$ & $32.4(8780)$ & $32.4(35118)$ \\
\hline \multicolumn{9}{|l|}{ Events during follow-up } \\
\hline Total deaths & 3.7 (481) & $4.7(2451)$ & $4.0(657)$ & $5.2(3377)$ & $0.9(171)$ & $1.9(1411)$ & $1.6(143)$ & $3.3(1164)$ \\
\hline Emigrations & $13.6(1765)$ & 3.8 (1977) & $14.3(2324)$ & $5.0(3212)$ & $17.6(3222)$ & $6.0(4458)$ & $22.9(2017)$ & $6.6(2333)$ \\
\hline $\begin{array}{l}\text { Median age at study end } \\
31 \text { December } 2007\end{array}$ & $44.3(37.1 ; 54.2)$ & $44.7(37.7 ; 54.5)$ & $43.5(37.0 ; 52.2)$ & $43.9(37.6 ; 52.4)$ & $36.8(32.1 ; 43.4)$ & $37.5(32.8 ; 44.1)$ & $36.9(32.8 ; 42.2)$ & $37.8(33.8 ; 43.3)$ \\
\hline Median follow-up in years & $12.1(10.3 ; 12.4)$ & $12.1(10.7 ; 12.5)$ & $11.9(9.7 ; 12.4)$ & $12.1(10.5 ; 12.5)$ & $10.6(9.0 ; 12.4)$ & $10.9(9.2 ; 12.6)$ & $10.5(9.0 ; 12.2)$ & $10.8(9.2 ; 12.4)$ \\
\hline
\end{tabular}


group of individuals from the Middle East we decided to define them as a separate group. Moreover, we excluded the former Yugoslavia from Eastern Europe because individuals from the Balkan in the 1990s mainly came due to the war rendering them a special group. Data on income were obtained from Statistics Denmark. The variable on income is updated annually on 31 December. Personal income was divided into three categories: low (<€13500/year), middle (€13 500-40 500/year) and high (>€40500/year). In total, 848 individuals, 113 refugees (controls: 224) and 368 immigrants (controls: 143) did not have a registered income by 31 December 2007. These individuals were excluded from our analysis, which was consequently based on 29026 refugees (controls: 116332) and 26766 immigrants (controls: 108 391).

\section{Statistical analysis}

We estimated the rate ratio (RR) and 95\% CIs for refugees and immigrants compared with their Danish-born controls using a Cox regression model (in SAS V.9.1), which was fitted separately for men and women. Native Danes form the reference group. The Cox regression analysis implies a continuous adjustment for age in the model. Further, the RR was analysed by both migrant status and region of birth and adjusted for income. The analyses take into consideration the time during which an individual has been in a certain income category and allow for people to change from one income category to another over time. We assumed that the effect of income on mortality was the same for refugees, immigrants and controls. Before making this assumption we analysed all interactions among migrant status, region of birth and income and found no significant interactions. First, we studied the unadjusted RR and then the RR adjusted for income. As these separate analyses gave the same conclusion, table 2 shows only the adjusted rates. Further, analyses split on region of origin are referred to only in the text. The Cox regression model allowed us to compare the RR for refugees with that of immigrants, and not only with that of their Danish-born controls. Last, because of the low number of homicides and suicides, only unintentional injuries are described by specific cause of injury and differences are tested using $\chi^{2}$ tests (table 3 ).

The Danish Data Protection Agency has approved the study. Further, ethical approval regarding registry-based research is not required in Denmark. ${ }^{23}$ The data set was made available and analysed in an anonymous form by remote online access to the data set stored at Statistics Denmark.

\section{RESULTS}

Table 1 shows characteristics of the study cohort distributed by migrant status and sex. The cohort had a median age at study end of around 44 years among refugees and 37 years among immigrants. The median follow-up time was approximately 12 years for refugees and approximately 11 years for immigrants. Among refugees, 44\% were women, and among immigrants $67 \%$ were women. Approximately half the refugees in the cohort came from the former Yugoslavia, while immigrants originated mainly from the Middle East and Asia.

Table 2 shows the RR of sex-specific injury mortality estimated by migrant status, adjusted for age and income. Compared with native Dames, suicide mortality was significantly lower for male refugees ( $R R=0.38 ; 95 \%$ CI 0.24 to 0.61$)$ and male immigrants ( $R R=0.24 ; 95 \%$ CI 0.10 to 0.59 ), whereas female refugees $(R R=0.80 ; 95 \%$ CI 0.40 to 1.61$)$ and female immigrants ( $R R=0.87 ; 95 \%$ CI 0.46 to 01.65 ) showed no significant differences. Analysed by region of origin (data not shown in table), suicide mortality was significantly lower for refugee men from the former Yugoslavia $(\mathrm{RR}=0.54 ; 95 \%$ CI 0.31 to 0.94 ) and Iraq ( $R R=0.11 ; 95 \%$ CI 0.01 to 0.75$)$ as well as for immigrant men from the Middle East ( $R R=0.22 ; 95 \%$ CI 0.05 to $0.87)$; the results for all other groups were non-significant.

Table 2 also shows that compared with native Danes, immigrant women ( $R R=3.09$; $95 \%$ CI 1.11 to 8.60 ) had a significantly higher homicide rate; all other groups showed non-significant differences. Analysed by region of origin (data not shown in table), homicide mortality was higher among refugee women from Sub-Saharan Africa ( $R R=8.55$; 95\% CI 1.09 to 67.21), albeit only on a borderline significant level. The results for all other groups were non-significant.

Last, table 2 shows the RR of mortality from unintentional injuries. Compared with native Danes, both female $(R R=0.44$; $95 \%$ CI 0.23 to 0.83 ) and male ( $R R=0.40 ; 95 \%$ CI 0.29 to 0.56$)$ refugees had significantly lower mortality from unintentional injuries. This was also true of immigrant women $(R R=0.40$; $95 \%$ CI 0.21 to 0.76$)$ and men $(R R=0.22 ; 95 \%$ CI 0.12 to 0.42$)$. Analysed by region of origin (data not shown in table), only refugee men from the former Yugoslavia $(R R=0.39 ; 95 \%$ CI 0.24 to 0.61 ) and Iraq ( $R R=0.30 ; 95 \%$ CI 0.13 to 0.68$)$ as well as immigrant men from the Middle East $(R R=0.27 ; 95 \%$ CI 0.11 to 0.61) had significantly lower unintentional injury mortality compared with that among native Danes; however, most other groups showed similar non-significant tendencies for both sexes.

Table 3 shows the frequency distribution of unintentional injury mortality by specific disease causes (ICD-10) among refugees and immigrants compared with their Danish-born controls. Male and female immigrants had higher mortality from falls compared with that among native Danes; no systematic differences were found for refugees. Refugees of both sexes and immigrant women had a higher mortality from traffic

Table 2 Rate ratio (RR) of sex-specific injury mortality estimated by migrant status, adjusted for age and income. Danish-born controls form the reference group. Analyses are based on data from 1 January 1994 to 31 December 2007

\begin{tabular}{|c|c|c|c|c|c|c|c|c|}
\hline \multirow[b]{2}{*}{ Injury type } & \multicolumn{4}{|c|}{ Refugees } & \multicolumn{4}{|c|}{ Immigrants } \\
\hline & $\overline{\mathbf{R R}}$ & $95 \% \mathrm{Cl}$ & $n$ & $\bar{p}$ Value & $\overline{\mathbf{R R}}$ & 95\%Cl & $n$ & $\bar{p}$ Value \\
\hline \multicolumn{9}{|c|}{ Intentional injuries } \\
\hline Women & 0.80 & (0.40 to 1.61$)$ & 10 & 0.5403 & 0.87 & (0.46 to 1.65 ) & 12 & 0.6609 \\
\hline Men & 0.38 & (0.24 to 0.61$)$ & 19 & $<0.0001$ & 0.24 & (0.10 to 0.59$)$ & 6 & 0.0019 \\
\hline \multicolumn{9}{|l|}{ Homicides } \\
\hline \multicolumn{9}{|c|}{ Unintentional injuries } \\
\hline Women & 0.44 & (0.23 to 0.83$)$ & 11 & 0.0113 & 0.40 & (0.21 to 0.76 ) & 10 & 0.0055 \\
\hline Men & 0.40 & $(0.29$ to 0.56$)$ & 40 & $<0.0001$ & 0.22 & (0.12 to 0.42 ) & 12 & $<0.0001$ \\
\hline
\end{tabular}


Table 3 Frequency distribution of unintentional injury mortality by specific death causes (ICD-10) among refugees and immigrants compared with their Danish-born controls. Analyses are based on data from 1 January 1994 to 31 December 2007

\begin{tabular}{|c|c|c|c|c|c|c|c|c|}
\hline \multirow[b]{2}{*}{ Unintentional injury types } & \multicolumn{4}{|l|}{ Refugees } & \multicolumn{4}{|l|}{ Immigrants } \\
\hline & $\begin{array}{l}\text { Female } \\
\%(\mathbf{n})\end{array}$ & $\begin{array}{l}\text { Control } \\
\%(\mathbf{n})\end{array}$ & $\begin{array}{l}\text { Male } \\
\% \text { (n) }\end{array}$ & $\begin{array}{l}\text { Control } \\
\% \text { (n) }\end{array}$ & $\begin{array}{l}\text { Female } \\
\% \text { (n) }\end{array}$ & $\begin{array}{l}\text { Control } \\
\%(\mathbf{n})\end{array}$ & $\begin{array}{l}\text { Male } \\
\% \text { (n) }\end{array}$ & $\begin{array}{l}\text { Control } \\
\%(\mathbf{n})\end{array}$ \\
\hline Falls & $10(1)$ & $15(12)$ & $7(3)$ & $7(20)$ & $20(2)$ & $9(7)$ & $18(2)$ & $9(14)$ \\
\hline Poisoning & $0(0)$ & $23(19)$ & $10(4)$ & $25(69)$ & $10(1)$ & $28(23)$ & $18(2)$ & $28(44)$ \\
\hline Other causes & $50(5)$ & $32(27)$ & $25(10)$ & 34 (92) & $30(3)$ & $29(22)$ & $37(4)$ & $35(54)$ \\
\hline Total & $100 \%(10)$ & $100 \%(83)$ & $100 \%(40)$ & $100 \%(270)$ & $100 \%(10)$ & $100 \%(82)$ & $100 \%(11)$ & $100 \%(155)$ \\
\hline
\end{tabular}

*The $\mathrm{p}$ value is estimated by a $\chi^{2}$ test and shows whether differences in all unintentional injury types between respectively migrants and their controls were significant or not. ICD-10, International Classification of Diseases, tenth revision.

unintentional injuries compared with native Danes; no difference was seen for immigrant men. However, mortality from poisoning was consistently lower among all migrant groups compared with that among native Danes. For 'other death causes', no systematic differences were observed. Only male refugees differed significantly in the distribution of injury types compared with their Danish-born controls $(p=0.03)$ whereas this was not the case for female refugees $(p=0.64)$. Male $(p=0.66)$ and female $(p=0.38)$ immigrants did not differ significantly compared with their Danish-born controls.

To increase power we combined both sexes where the results pointed insignificantly in the same direction. Consequently, we found an RR of 0.84 (95\% CI 0.52 to 1.34 ; $\mathrm{p}=0.46$ ) of suicide for refugees combined compared with Danish-born and a homicide RR of 1.95 (95\% CI 0.93 to $4.1 ; \mathrm{p}=0.46)$ for refugees combined compared with Danish-born. Aggregated analyses could not contribute to other conclusions for the remaining analyses of intentional and unintentional mortality data, which is why all analyses are shown separately by sex.

\section{DISCUSSION}

Our main results show that compared with native Danes, suicide mortality was significantly lower among male refugees and immigrants, whereas their female counterparts showed no significant differences. However, immigrant women had a significantly higher homicide rate than native Danes did: no other groups showed significant differences. Last, refugees and immigrants of both sexes had lower mortality from unintentional injuries compared with native Danes. Differences by region of origin were found for both intentional and unintentional mortality outcomes.

\section{Methodological strengths and limitations}

We used the unique Danish possibilities of cross-linkage between several different national registers. This enabled us to identify a large cohort of refugees and family reunited immigrants based on specific information from the immigration authorities on migrant type and also enabled us to divide refugees and immigrants according to seven geographical subgroups. The design allowed us to calculate death rates over a follow-up period of up to 12 years and enabled us to compare directly with a matched group of native Danes.

There are several factors that may have influenced the results of this study. First, it is important to stress the exploratory nature of the study due to the small numbers. Although the study is based on a relatively large cohort of migrants, absolute numbers become relatively small when the specific injury mortalities are investigated and stratified according to region of birth and migrants status. Despite this power problem, our analyses were significant. However, further analysis according to causes of unintentional injuries was only possible in the form of a frequency distribution (table 3). Second, the Register on Causes of Death did not receive death certificates for 3\%-4\% of all the annual deaths that were registered in the Population Register at Statistics Denmark. Third, 1.7\% (168/9855) of all deaths studied for cause-specific mortality had 'unknown' cause of death listed. Consequently, there may be differences between migrants and native Danes regarding the distribution of these unknown death causes, but these differences are not likely to be substantial as the 168 deaths are fairly equally distributed over migrants and controls. Last, our results may also have been affected by registered or unregistered remigration, which would have skewed the denominator figures. Thus, remigration of healthy individuals may have inflated our results, whereas remigration of critically ill individuals with infectious diseases who then die abroad would have led to an underestimation (the so-called 'remigration bias'). We had no means of taking these biases into consideration as we did not know the extent of remigration in relation to these two points. Deaths abroad of individuals with a Danish personal identification number are reported to the Danish authorities on an irregular basis. Those death certificates sent to the Register of Death Causes are not included due to validity problems.

\section{Discussion of findings}

Our results showed a protective effect of being a migrant on suicide mortality, albeit only significantly so for men. Although the results are based on very small numbers, they are supported by some European studies, ${ }^{8} 2124$ but in contrast to others. ${ }^{25}$ For example, a Danish study showed that male residents with foreign citizenship in Denmark had a lower risk of suicide compared with male Danish citizens. ${ }^{26}$ These results are contra-intuitive in that research has established higher rates of mental health problems among migrants of both sexes, which is explained by the strain of trauma, prolonged asylum procedures, loss of identity and the stress of re-establishing life in the immigration country. ${ }^{10-12}$ Additionally, rates of suicidal behaviour are higher among migrants than among natives. ${ }^{27} 28$ What could explain our results? Studies show that some nonWestern migrants have stronger cultural and religious norms, which make suicide-selection less acceptable and therefore discourages individuals despite mental health problems. ${ }^{29} 30$ Our study enabled us to divide by migrant status, and previous studies of our cohort have indeed shown more mental disorders among refugees compared with family reunited immigrants. ${ }^{9} 31$ Contrary to our expectations, we found only a minor protective effect of family reunification compared with refugee status. 
Second, our results showed non-significant tendencies towards a higher mortality from homicide among immigrant women. Our findings are based on very small numbers, which warrants caution when interpreting them. Two Dutch studies also found a higher homicide rate among migrants of both sexes compared with native Dutch. ${ }^{7}$ A higher mortality from homicide among migrants may be attributed to several interrelated factors, including the psychosocial stress of re-establishing life in a new context, lower socioeconomic position, differences in cultural norms and higher involvement in criminal affairs among migrants. A recent Danish study showed that male first-generation migrants and descendants from nonWestern countries had a higher involvement in all criminal activities compared with that among native Danes with a similar socioeconomic background. ${ }^{32}$

Finally, our results showed consistently lower rates of unintentional injury mortality among all groups of migrants compared with that among the Danish-born. This is supported by a Danish study on unintentional injuries that found lower rates of injuries treated at emergency departments among migrants' children compared with children of native Danes. ${ }^{19}$ The literature shows that unintentional injury mortality differs according to unintentional injury type..$^{7-9}$ We preformed an analysis of the causes of unintentional injuries to understand our results better; however, due to small numbers we could only make a $\chi^{2}$ tested frequency distribution. The only significant finding was differences between male refugees and Danish-born. Male refugees died more from traffic injuries whereas Danishborn especially died more from poisoning, including poisoning from medicine, drugs and alcohol. These results are supported by the literature on risk behaviour, which shows low alcohol and drug consumption among migrants compared with the host populations. $^{1833}$

In conclusion, our study is exploratory in nature being limited by numbers; however, the results suggest interesting trends in injury-related mortality. Overall results were advantageous to

\section{What is already known on the subject}

- The few studies investigating injury mortality among European migrants show increased mortality for all injuries combined; albeit differences were seen according to type of injury, ethnic group, sex and age.

\section{What this study adds}

In contrast to our expectations, our results showed consistently lower rates of unintentional and intentional injury mortality, apart from homicide mortality, among migrants compared with that among the Danish-born.

- This study is the first in a European context to explore injury mortality using migrant status (refugees versus immigrants) and not merely ethnic background (country of origin).

- Our study used the unique Danish possibilities of performing register-based studies on national data; moreover, we were able to distinguish as intentional and unintentional injury types. migrant groups, apart from homicide mortality. Future research needs to further explore injury patterns in larger populations also using less severe injury outcomes. Moreover, research including qualitative studies should concentrate on investigating which protective factors are important among migrants compared with natives. Such research may also benefit injury prevention in the majority population.

Acknowledgements We would like to thank the Danish Immigration Service for their help establishing the population cohort.

Contributors MN: conception, design, acquisition of data and interpretation of data drafting of the manuscript, final approval given. MO and JHP: analysis, drafting of the manuscript, final approval given. BL: design, drafting of the manuscript, final approval given. AK: design, interpretation of data, drafting of the manuscript, final approval given.

Funding This work was supported by TrygFonden (no specific grant number).

\section{Competing interests None.}

Provenance and peer review Not commissioned; externally peer reviewed.

Open Access This is an Open Access article distributed in accordance with the Creative Commons Attribution Non Commercial (CC BY-NC 3.0) license, which permits others to distribute, remix, adapt, build upon this work non-commercially, and license their derivative works on different terms, provided the original work is properly cited and the use is non-commercial. See: http://creativecommons.org/licenses/by-nc/3.0/

\section{REFERENCES}

1. Statistics Denmark. Immigrants in Denmark 2010. Copenhagen: Statistics Denmark, 2011

2. The Danish Immigration Service. Facts and Figures on Immigration 2006 Copenhagen: The Danish Immigration Service, 2007.

3. The Danish Immigration Service. Facts and Figures on immigration 2009 Copenhagen: The Danish Immigration Service, 2010.

4. Bos V, Kunst A, Garssen J, et al. Socioeconomic inequalities in mortality within ethnic groups in the Netherlands, 1995-2000. J Epidemiol Community Health 2005; 59:329-35.

5. Gadd M, Johansson SE, Sundquist J, et al. Are there differences in all-cause and coronary heart disease mortality between immigrants in Sweden and in their country of birth? A follow-up study of total populations. BMC Public Health 2006;6:102.

6. Razum 0, Zeeb H, Seval Akgün H, et al. Low overall mortality of Turkish residents in Germany persists and extends into a second generation: merely a healthy migrant effect? Trop Med Int Health 1998;3:297-303.

7. Stirbu I, Kunst $A E$, Bos $V$, et al. Injury mortality among ethnic minority groups in the Netherlands. J Epidemiol Community Health 2006;60:249-55.

8. Bos V, Kunst $A E$, Keij-Deerenberg IM, et al. Ethnic inequalities in age- and causespecific mortailty in the Netherlands. Int J Epidemiol 2004;33:1112-19.

9. Kyobutungi C, Ronellenfitsch U, Razum 0, et al. Mortality from external causes among ethnic German immigrants from former Soviet Union countries, in Germany. Eur J Public Health 2006;16:376-82.

10. Norredam M, Garcia-Lopez A, Keiding N, et al. Risk of mental disorders in refugees and native Danes: a register-based retrospective cohort study. Soc Psychiatry Psychiatr Epidemiol 2009;44:1023-9

11. Hallas $\mathbf{P}$, Hansen AR, Staehr MA, et al. Length of stay in asylum centres and mental health in asyum seekers: a retrosective study from Denmark. BMC Public Health 2007;11:288

12. Cantor-Graae E, Pedersen CB, McNeil TF, et al. Migration as a risk factor for schizophrenia: a Danish population-based cohort study. Br J Psychiatry 2003; 182:117-22.

13. European Union Minorities And Discrimination Survey. European Union Agency for Fundamental Rights. Bruxelles: European Union Agency for Fundamental Rights, 2009.

14. OECD. International migration Outlook. OECD, 2011

15. Norredam M, Mygind A, Krasnik A. Access to health care for asylum seekers in the European Union-a comparative study of country policies. Eur J Public Health 2006;16:286-90.

16. Crosby SS, Norredam M, Paasche-Orlow MK, et al. Prevalence of torture survivors among foreign-born patients presenting to an urban ambulatory care practice. J Gen Intern Med 2006;21:764-8.

17. Norredam ML, Nielsen AS, Krasnik A. Migrants' access to healthcare. Dan Med Bull 2007:54:48-9.

18. Singhammer J. Ethnic Minority Health-A Survey Based Study [Etniske minoriteters sundhedsprofil]. Århus: Region MidJutland, 2008

19. Laursen B, Moller H. Unintentional injuries in children of Danish and foreign-born mothers. Scand J Public Health 2009;37:577-83.

20. Norredam M, Garcia-Lopez A, Keiding N, et al. Excess use of coercive measures in psychiatry among migrants compared with Danish born. Acta Psychiatr Scand 2010;121:143-51. 
21. Osler M, Nybo Andersen AM, Lauersen B, et al. Cognitive function in childhood and early adulthood and injuries later in life: the Metropolit 1953 male birth cohort. Int J Epidemiol 2007;36:212-19.

22. World Health Organisation (WHO). List of Member States by WHO Region and Mortality Stratum. Copenhagen: The World Health Report, 2003.

23. Thygesen LC, Daasnes C, Thaulow I, et al. Introduction to Danish (nationwide9 registers on health and social issues: structure, access, legislation, and archiving. Scand j Pub Health 2011;39:12-16.

24. Johansson LM, Sundquist J, Johansson SE, et al. Suicide among foreign born minorities and native swedes: an epidimiological followup study of a defined population. Soc Sci Med 1997;44:181-7.

25. Ferrada-Noli MA. cross-cultural breakdown of Swedish suicide. Acta Psychiatr Scand 1997:96:108-16.

26. Andrés AR, Collings S, Qin P. Sex-specific impact of socio-economic factors on suicide risk: a population-based case-control study in Denmark. Eur J Pub Health 2010;20:265-70.

27. Burger I, van Hemert AM, Schudel WJ, et al. Suicidal behaviour in four ethnic groups in the Hague, 2002-2004. Crisis 2009;30:63-7.
28. Mirsky J, Kohn R, Dolberg P, et al. Suicidal behaviour among immigrants. Soc psychiatry Psychiatr Epidemiol 2011;46:1133-41.

29. Neeleman J, Wessely S, Lewis G. Suicide acceptability in African- and white Americans: the role of religion. J Nerv Ment Dis 1998;186:12-16.

30. Neeleman J, Halpern D, Leon D, et al. Tolerance of suicide, religion and suicide rates: an ecological and individual study in 19 countries. Psychol Med 1997:27:1165-71.

31. Norredam M, Garcia-Lopez A, Keiding N, et al. Risk of mental disorders in family reunification migrants and native Danes: a register-based historically prospective cohort study. Int J Public Health 2010;55:413-19.

32. Højsgaard Andersen L, Tranæs T. Ethnic Minoritites' Overrepresentation In Criminal Cases [Etniske minoriteters overrepræsentation i strafferetlige domme]. Rockwool Fondens Forskningsenhed: Syddansk Universitetsforlag, 2011.

33. Bécares L, Nazroo J, Stafford M. The ethnic density effect on alcohol use among ethnic minority people in the UK. J Epidemiol Community Health 2011:65:20-5

\section{Inflatable bounce house injuries}

A report in Pediatrics shows that a design overhaul of children's inflatable bounce houses is needed because about 30 children per day in the USA are injured while playing in them. Between 1995 and 2010 there was a 15-fold increase in the number of such injuries especially in recent years. The U.S. Consumer Product Safety Commission recommends that children under 6 not be allowed to use full-size bounce houses. The authors, headed by Gary Smith, called for better guidelines for use and for design changes.

\section{Record low homicides in New York}

Murders in New York City have dropped to their lowest level in over 40 years. The actua number is 414 homicides in 2012, compared with 515 for 2011. In the 1990s the totals were in the 2000s. The Mayor credited the department's controversial practice of stopping people on the street and questioning them as well as aggressive hot-spot policing. Against this good news is the fact that 20 children were murdered. Nevertheless, total killings have dropped so low that there are now more suicides than homicides. The commissioner said 'he believed that relatively new policing strategies, including adding more police officers dedicated to curbing domestic violence, and monitoring social media to thwart gang-related murders, were working.'

\section{Magnets banned}

An Australian report states that small, high powered magnets that can cause serious injury or death if swallowed by children have been permanently banned. The products that contain numerous small, high-powered magnets are marketed as toys, games or puzzles. The problem is 'If a young child swallows more than one of these high-powered magnets they can attract to each other across the intestinal wall and perforate the intestine, leading to serious injury or possibly death. Teenagers have also needed surgery after using these magnets to imitate mouth or tongue piercings.'

From Richard Hockey 